\title{
Physical Exercise Activity, Cognitive Functions and Its Relationship to Quality of Life in the Senior Citizens of Lahore
}

\author{
Hamid Mahmood ${ }^{1,}$, Ammara Waqar², Saleem Rana ${ }^{1}$, Muhammad Yaqoob ${ }^{1}$, \\ Ejaz Mahmood Ahmad Qureshi ${ }^{1}$, Syed Amir Gillani ${ }^{1}$, Asif Hanif ${ }^{1}$, Awais Gohar ${ }^{3}$ \\ ${ }^{1}$ University Institute of Public Health, The University of Lahore, Lahore, Pakistan \\ ${ }^{2}$ Quality Enhancement Cell, Al-Aleem Medical College, Lahore, Pakistan \\ ${ }^{3}$ Primary and Secondary Health Department, Government of the Punjab, Lahore, Pakistan
}

\section{Email address:}

drhamidmahmood373@gmail.com (H. Mahmood), ammarahamid24@gmail.com (A. Waqar), saleem.uiph@gmail.com (S. Rana), yaqoobchich@yahoo.com (M. Yaqoob), ejaz_qureshi@hotmail.com (E. M. $\Lambda$. Qureshi), profgilani@gmail.com (S. $\Lambda$. Gillani), asif.hanif@ahs.uol.edu.pk (A. Hanif),dr.awais.gohar@gmail.com (A. Gohar)

${ }^{*}$ Corresponding author

\section{To cite this article:}

Hamid Mahmood, Ammara Waqar, Saleem Rana, Muhammad Yaqoob, Ejaz Mahmood Ahmad Qureshi, Syed Amir Gillani, Asif Hanif, Awais Gohar. Physical Exercise Activity, Cognitive Functions and Its Relationship to Quality of Life in the Senior Citizens of Lahore. American Journal of Biomedical and Life Sciences. Vol. 8, No. 5, 2020, pp. 143-155. doi: 10.11648/j.ajbls.20200805.14

Received: August 15, 2020; Accepted: August 26, 2020; Published: September 16, 2020

\begin{abstract}
There is long debate on the proper functioning of senior citizens with relation to different factors which affect the physical exercise activity and cognitive functions in the senior citizens to perform their activities in daily life. Research had been carried out on relationship of physical exercise activity (recent and long term) to perform ADL and IADL. The objectives of the study are: To find out the composite score (z-scores) to check the executive functions of ADL and IADL. To find out the impact of recent and long term physical exercise activities and cognitive executive functions by using $z$-scores to measure the quality of life in male and female senior citizens. The results of our study show that the recent physical exercise activity does not improve the cognitive functions in the senior citizens through perform ADL and IADL. However long term physical exercise activity improve the cognitive functions in the senior citizens. the females who were having better physical exercise activity have better cognitive functions as compare to male with the same physical exercise activity. It has been found out that the physical exercise activities are important to be performed by the senior citizens to keep their cognitive executive functions intact. The senior citizens who are engaged in the physical exercise activities are less likely develop cognitive development in the old age. Physical exercise activities in the long term have great impact in maintaining the cognitive function in the senior citizens to perform ADL and IADL.
\end{abstract}

Keywords: Physical Exercise Activities, Cognitive Functions, Socio-Cultural Activity, Senior Citizen, Gender, ADL, IADL

\section{Introduction}

The old age population is on the rise exponential around the world. There is need to find out its relationship which can affect the physical exercise activity and cognitive functions to perform activities of daily living and instrumental activities of daily living.

Aging is process which begins at conception and progress till death. It is irreversible, chronological in aspects. During the process of aging, the brain passes through different atomically and physiological changes that bring changes in our intellectual properties and cognitive functions. Aging brings decline in our cognitive functions which may lead to reduction in our activities of daily living (ADL) and instrumental activities of daily living (IADL). The inability may be partial disability to perform ADL and IADL, which shows cognitive impairment.

Saracli et al. defines the successful aging as "the process of keeping a person physically, mentally, emotionally and psychologically health during the process of aging. The decline in the quality of life, due to partial or complete 
disability, to perform executive cognitive functions is called cognitive impairment". [1]

The physical exercises activities, socio-cultural activities, socio-demographic variables play important role in the development or prevention of cognitive decline. Relationship of physical exercise activities and its effect on cognitive executive functions have yet not been studied in Pakistan. It is therefore, important that the impact of recent and long term physical exercise activities on the cognitive executive functions in the old adult should be studied that may provide us new avenues for research.

\section{Theoretical Background}

The aging population is passing through difficult time due to COVID-19 pandemic throughout the world. Most of the senior citizens above the age of 65 having comorbid diseases prior to COVID-19 pandemic are most likely to suffer to death. It is therefore important that the relationship of physical exercise activities and cognitive executive functions must try to be restored in order to keep healthy aging.

Andel et al. carried out a research on the role of midlife occupational complexity and leisure activity in late-life cognition. He found out that the leisure activities improve the physiological of wellbeing of senior citizens which keep them involve to perform IADL. [2]

Gow et al. carried out a study regarding life course activity participation from early, mid, and later adulthood as determinants of cognitive aging. He found out that the physical exercise activities for long term in any part of life produce good effects on cognitive health of a person. [3]

Prakash et al. carried out a study to find out the relationship between Physical activity and cognitive vitality. He was of the view that the physical activity and cognitive vitality are interdependent on one and other. [4]

Kareholt et al. carried out a cohort study to find out the Baseline leisure time activity and cognition more than two decades later. He found out that long term impact of the physical activity and leisure time activity plays an important role in maintaining the cognitive health in the older adults. [5]

Abou-Dest et al. carried out a research about the innovation of activities of daily life. He found out that the task was impaired due to motor inhibition of the parasympathetic function. [6]

Etnier \& Chang carried out a research to find out the difficulties in the senior citizens to perform activities of daily living. He concluded that executive functions are impaired either due to mal functioning of parasympathetic nervous system or endocrine system. [7]

Different studies have been carried out to assess the cognitive functions by using different sets. The score of these results were used to find out the person's ability to carry out different activities of daily living as well as instrumental activities of daily living.

Barnes et al. carried out a randomized controlled trial to enhance cognitive function in older adults. He used the mental Activity and exercise (MAX) tool to measure the impact of the cognitive functions. He found out that the cognitive functions can be improve by the physical exercise activities in the older adults. [8]

Barnes et al. carried out a research to find out on social resources and cognitive decline in a population of older African Americans and whites. He was of the view that the social interaction and resources are important to maintain cognitive functions in the senior citizens. [9]

Oswald et al. wants to find out differential effects of single versus combined cognitive and physical training with older adults. This was long cohort study for 5- year. The results show the physical exercise activities in the long term are preserving the cognitive health in the senior citizens. [10]

Wilson et al. carried out a study on factors of the Loneliness and risk of Alzheimer disease. He was of the view that the loneliness in the older adults greatly impact on the cognitive functions in the senior citizens. [11]

Different tests has been used to measure of information processing speed, associative ability, inhibition, selective attention, mental flexibility, working memory, perceptual comparison speed and nonverbal abstract reasoning (e.g. the ability to think, think, and act).

Arbuthnott \& Frank used a trail making test, part B to measure the executive control validation using a setswitching paradigm. He found out that the test use was able to measure the executive control in the clinical experimental settings. [12]

Kortte et al. used the trail making test, part B cognitive flexibility or ability to maintain set. He found out that this test can be used to measure the cognitive ability of a person in the clinical settings. [13]

Pachana et al. carried out a study on California Older Adults using Stroop test. This test proved to be successful in clinical setting to measure cognitive functions in the older citizens. [14]

Salthouse et al. carried out different studies using Digit Symbol Substitution Test, matrix reasoning test and Executive functioning test to measure age related cognitive decline in normal adults. These entire tests were used in clinical settings to measure the cognitive ability of senior citizens. [15]

Makizako et al. 112017 developed a Predictive Cutoff Values of the five-times Sit-to-Stand Test and the Timed "Up \& Go" Test for Disability Incidence in Older People Dwelling in the Community. He found out that the test provided physical exercise activity in the senior citizens which brought improvement in their cognitive functions. [16]

Oreska et al. 82020 wanted to know the effectiveness of two different multimodal training models on physical performance in the elderly. He found out that the structured physical exercise activities can improve the mobility and the cognitive functions in the elderly persons. [17]

Our study is based on the composite score using different tests which were converted into z-scores to check the executive functions of ADL and IADL in the senior citizens. 


\section{Objectives of Study}

The objectives of the study are:

1. To find out the composite score (z-scores) to check the executive functions of ADL and IADL.

2. To find out the impact of recent and long term physical exercise activities on physical mobility and cognitive executive functions by using z-scores to measure the quality of life in male and female senior citizens.

\section{Hypotheses}

H1: Effect of physical exercise on cognitive decline in the old age

H1-a: Recent physical exercise can limit age-related cognitive decline.

H1-b: Long-term physical exercise can limits age-related cognitive decline.

$\mathrm{H} 2$ : Moderating role of gender on the impact of physical exercise on cognitive decline.

H2-a: Recent physical exercise has a greater impact on cognitive aging in female as compare to male.

H2-b: Long-term physical exercise has a greater impact on cognitive aging in female as compare to male.

\section{Methodology}

Settings: This study has been conducted in District Lahore, Pakistan.

Duration of Study: Six Months from November 2019 to April 2020.

Sampling Technique: The data has been collected from senior citizens, health care givers, Old Homes Administrators, Social Welfare Organizations, Hospitals, Non-Government Organizations, Old People Homes and community at large.

\section{Sample Selection}

Inclusion Criteria: All persons who have age of 21 years and above, male or female are included in the study.

Exclusion Criteria: All Persons (Male/Female) having age less than 21 years has excluded from the study.

Study Tools:

Sample size $(n)=137$

The total numbers of participants were 137 which included 69 females and 68 males which further divided in to 6 groups from 21 years to 80 years with an interval of 10 years.

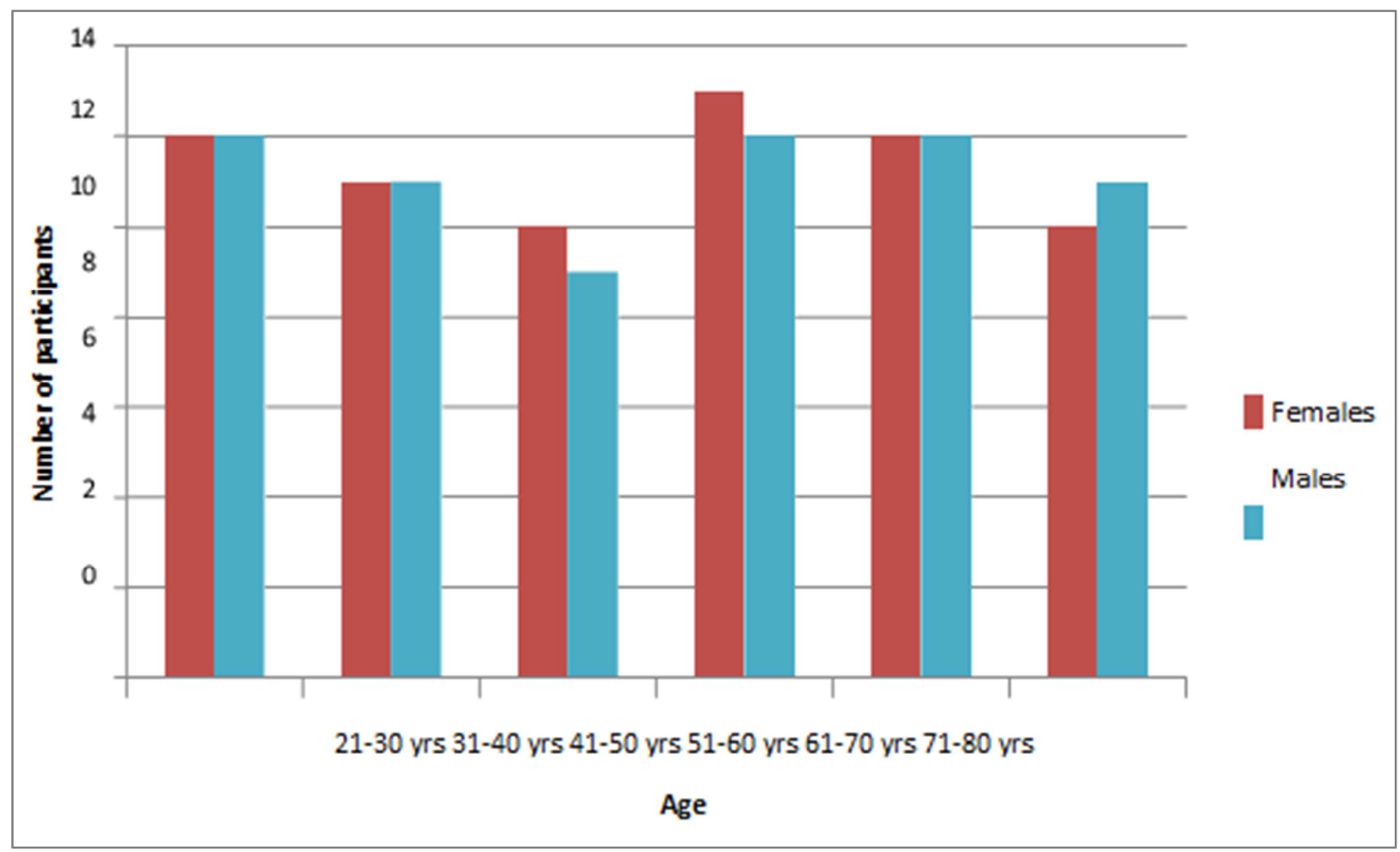

Figure 1. Distribution of the sample by age and gender in the study.

The confounding variable create biasness in the results and therefore needs to be checked by using Beck's depression scale [18]. the Mini-mental Status Examination (MMSE) was performed in persons having age greater than 51 years and who did not show (MMSE >26) [19] were included in the study. The senior citizens who were taking medication for cognitive impairment were also excluded as it can bring false interpretation in Stroop's test. All participants were checked for normal hearing and vision to be included in the study.

\subsection{Procedure}

\subsubsection{Recent Physical Exercise Activities}

Recent physical exercise activates has been measure and being converted to composite score for measurement. The data was collected from the recent physical exercises scores. The result has to be obtained of the recent physical exercise using the following formula: 
$\frac{\Sigma \text { Hours of Physical Practice (HPP) }}{52 \text { (i.e.,number of weeks per year) }}$

The total energy expenditure was needed to be calculated by multiplying the number of hours of physical exercise activity to its estimated metabolic cost. The classification of physical activity intensity has been provided by the Ainsworth et al. [20] The detail of which have been provided in the Table 1.

$$
\frac{\Sigma(\text { HPP } 1 * \text { MET } 1)+(\text { HPP } 2 * \text { MET } 2) \ldots(\text { HPPn } * \text { METn })}{52}
$$

The Metabolic Equivalent Task ("MET") has been express in terms of energy expenditure indicator. The term MET per week is very important to measure in order to find out the energy expenditure indicator.

\subsubsection{Long-term Physical Exercises Activities}

Long-term physical exercise activity has been assessed using PSCQL-MT scale. The questionnaire has been used to measure the physical exercise activities carried out by the different age groups i.e. 21-30 years, 31-40years, 41-50 years and 51 years and above.

The average scores have been obtained on the bases of average number of hours of weekly physical exercise activities since the age of 21 can be reproduced as under:

$\frac{\sum \text { HPP since the age of } 21}{\frac{\text { Number of years since the age of } 21(\text { i.e.,age }-20)}{52}}$

the overall average METs per week related to the physical exercise activity practiced since the age of 21 years was calculated according to the following formula:

$\underline{\Sigma(\text { HPP } 1 * \text { MET } 1)+(\text { HPP } 2 * \text { MET } 2) \ldots(\text { HPPn } * \text { METn })}$ Number of years of coverage (i.e.,age -20 )

Table 1. Basic scale of metabolic equivalence task (MET) (inspired by Ainsworth et al., 2000).

\begin{tabular}{|c|c|c|c|c|}
\hline Very Low $\leq 3$ METS & Low $>3$ METS and $\leq 5 \mathrm{METS}$ & Medium $>5$ METS and $\leq 7$ METS & High $>7$ METS and $\leq 9$ METS & Very high $>9$ METS \\
\hline $\begin{array}{l}\text { Domestic activities } \\
\text { To take a shower } \\
\text { Get dressed } \\
\text { Iron } \\
\text { Dust off }\end{array}$ & $\begin{array}{l}\text { To vacuum } \\
\text { Carrying loads }<6 \mathrm{~kg} \text { when } \\
\text { climbing stairs }\end{array}$ & $\begin{array}{l}\text { Carry loads of } 7 \text { to } 10 \mathrm{~kg} \text { when } \\
\text { climbing the stairs }\end{array}$ & $\begin{array}{l}\text { Carrying loads of } 11 \text { to } 22 \mathrm{~kg} \\
\text { when climbing the stairs }\end{array}$ & $\begin{array}{l}\text { Carrying loads of } 22 \text { to } \\
33 \mathrm{~kg} \text { when climbing } \\
\text { stairs }\end{array}$ \\
\hline Training and sports activities & & & & \\
\hline $\begin{array}{l}\text { Walk } 4 \mathrm{~km} / \mathrm{h} \\
\text { Stretching } \\
\text { Cycling }\end{array}$ & $\begin{array}{l}\text { Walk } 6 \mathrm{~km} / \mathrm{h} \\
\text { Light gymnastics } \\
\text { Aerobics }\end{array}$ & $\begin{array}{l}\text { Rapid walk } 7 \mathrm{~km} / \mathrm{h} \\
\text { Walk uphill } 5 \mathrm{~km} / \mathrm{h} \\
\text { Swimming } \\
\text { Fencing }\end{array}$ & $\begin{array}{l}\text { Intense gymnastics } \\
\text { Swimming (Slow Crawl) } \\
\text { Singles tennis }\end{array}$ & $\begin{array}{l}\text { Race }(11 \mathrm{~km} / \mathrm{h}) \\
\text { Swimming (Butterfly) } \\
\text { Handball } \\
\text { Squash } \\
\text { Badminton }\end{array}$ \\
\hline $\begin{array}{l}\text { Hobbies } \\
\text { Light Gardening } \\
\text { Car driving } \\
\text { Travel }\end{array}$ & $\begin{array}{l}\text { Gardening } \\
\text { Walk, run with children } \\
\text { Playing games }\end{array}$ & $\begin{array}{l}\text { Gardening } \\
\text { DIY }\end{array}$ & $\begin{array}{l}\text { Do It Yourself (DIY): } \\
\text { Heavy work } \\
\text { Move }\end{array}$ & \\
\hline
\end{tabular}

\subsection{Executive Cognitive Functions}

The executive cognitive functions are the ADL and IADL which are necessary to perform to meet with the daily needs of life. The cognitive functions begin to decline after the age of 60 years and are badly impaired after the age of 70 years. It is therefore important that the executive cognitive functions in the senior citizens need to be assessed. The following tests are being used by the different psychologist to assess the functioning of senior citizens.

\subsection{Matrix Reasoning Test}

The Matrix reasoning test: This test is a sub-part of the Wechsler Abbreviated Scale of Intelligence (WAIS). It consists of 37 plates, of which the first two are examples. On each plate, a set of shapes is presented, one of which is missing (see Figure 2). Participants are asked to identify which shape would best complete this incomplete set, from the five options below.

The maximum response time for each board is 30 seconds. After three errors (or lack of response), the experimenter interrupts the test. The test score corresponds to the gross number of correct answers given by the participant. This test measures inductive reasoning which is a high-level executive function strongly involved in daily tasks and particularly sensitive to age-related deficits.

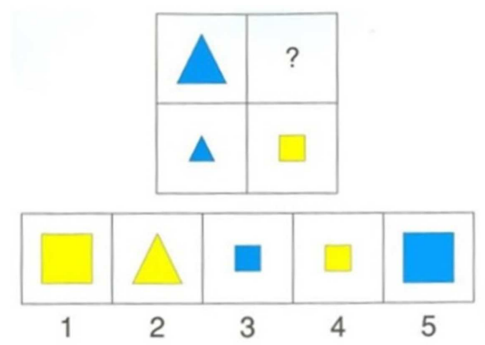

Figure 2. Extract from the "Matrix reasoning test".

\subsection{Stroop Tes [21]}

Etnier \& Chang carried out Stroop test which was previously been developed by the Stroop. For the purpose of study modified two plates version into four plates' version. [7] Scarpina \& Tagini used boards which have many words and colours to be presented to the senior citizens for identification in just 45 seconds. [22] The participants were asked to correct the error before moving to the next board. At 
the end of the test the total number of correct responses are calculated.

The first condition consist in naming the colors of the boxes (i.e., blue, green, yellow or red) (see Figure 3). The total numbers of correct responses have been calculated to find out the cognitive executive functions in the senior citizens.

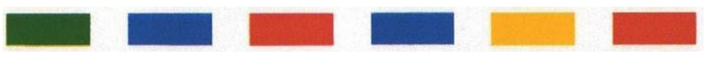

Figure 3. Extract from Plate 1 (neutral condition) of the "Stroop Test".

The second plate relates to the different words given below in Figure 4. The total numbers of correct responses have been

calculated to find out the cognitive executive functions in the senior citizens.

\section{GREEN YELLOW RED GREEN BLUE RED YELLOW}

Figure 4. Extract from Plate 2 (neutral condition) of the "Stroop Test".

In the third board matched color have been used to be read by the participants it needs to correctly identify the color as well as the word to interpreted the color. The total numbers of correct responses have been calculated to find out the cognitive executive functions in the senior citizens. See Figure 5.

GREEN BLUE RED BLUE GREEN YELLOW RED BLUE RED

Figure 5. Extract from Plate 3 (condition of inhibition) of the "Stroop Test".

The last two boards contains mix colours and the words which need to be identified by the participants. The color is different and the word presenting color is different so the participants have to identify which are match and which are not match as shown in Figure 6.

\begin{tabular}{lllllll|} 
Yellow GREN RED RED BLE & BELLOW RED GREEN \\
\hline
\end{tabular}

Figure 6. Extract from Plate 4 (condition of mental flexibility) from the "Stroop Test".

The Stroop test is an important step in recognition in cognitive functions in senior citizens even with low education or literate. The board one and two are easy to identify by the person to able to perform ADL but they cannot identify properly the board three and four. The persons who can perform on all the boards are able to perform ADL as well as IADL. Diamond defined inhibition as an ability to control once thought, emotions and behavior through internal predisposition according to external change.[23] According to him that the performance in board one and two and board three and four are very different which provided two cognitive scores which are being included in the calculation of the concluded score. Both these scored correspond to the total number of correct responses produced by the participants in the test.

\subsection{Digit Symbol Substitution Test (DSST)}

This is a paper based test in which digital symbol codes from 1 to 9 is used the test consists of eight lines of 20 boxes, each with numbers presented in random order. The instruction is to draw the corresponding symbol under each of the figures. Participants are asked to proceed in the order proposed by the test, in other words subjects are not allowed to fill in every 1 , then every 2 , etc. The first seven boxes of the test correspond to the example (see Figure 7). Once it is completed, the participant has 2 minutes to fill in as many boxes as possible. The DSST score corresponds to the gross number of correct responses noted.

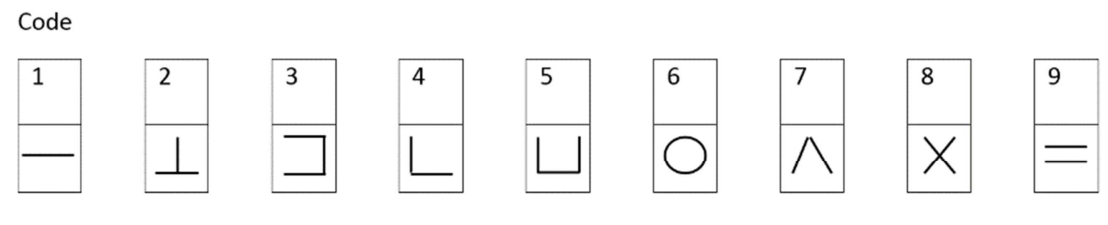

Exemples

\begin{tabular}{|l|l|l|l|l|l|l||l|l|l|l|l|l|l|l|l|l|l|l|l|}
\hline 2 & 1 & 3 & 7 & 2 & 4 & 8 & 2 & 1 & 3 & 2 & 1 & 4 & 2 & 3 & 5 & 2 & 3 & 1 & 4 \\
\hline & & & & & & & & & & & & & & & & & & & \\
\hline
\end{tabular}

Figure 7. Extract from the "Digit Symbol Substitution Test".

Success in DSST requires good capacities for perceptual and cognitive speed. Speed of information processing, memory processes and the speed of execution of movement would also be involved in this task. The diversity of the functions measured by this test refers to the complexity of precisely isolating an executive function.

\subsection{Trail Making Test}

This is also a paper based test which is mostly used in the Army Battery Test. It consists of two parts A and B. In part A the number tablets are randomly distributed on a paper. Participants are asked to connect 1 to 25 tablets previously 
written without lifting the pen.

In the part B the number and letters are given. The objective is to connect the numbers and the letters in the alphabetical order such as 1 related to A, 2 related to B and so on. See Figure 8. In case of error the participants is asked to return to the previous tablet to complete his trajectory correctly. The time is calculated for both parts of the test separately. The time difference between Part B - Part A provides the information about the perception and response time to conduct the executive functions. Hence it can be said that the score attained is the difference in time between Part B - Part A. In order to calculate the composite cognitive score, the TMT scores are multiply by -1 . A High reflects better cognitive functions.

a. Part $\mathrm{A}$

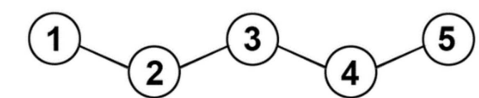

a. Part B

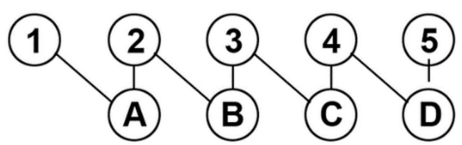

Figure 8. Extract from the Trail Making Test.

\subsection{Socio-cultural Level (SCL)}

It has been considered that the social cultural and economic conditions can contribute a lot in maintenance of executive functions of the activities of daily living and IADL in males and females in their old age. Rouillard et al. [24] carried out a research about the relationship between executive functions with relation to education level of the subject index. He was of the view that the level of education is directly proportion to the cognitive function in the senior citizens. Chung-Yi \& Wu [25] carried out a study about the technical skills in the senior citizens with related to their job. He found out that the professional skills prevent the cognitive decline in the senior citizens. Another study has been carried out to find out the present education system and the previous education systems in the 50 s of the last century. It has been observed that the present generation have better education and skills as compare to senior citizens. It is due to the reason that they may have low cognitive decline as compare to the senior citizen.

Fujishiro et al. [26] carried out a study on the factor of occupation cognitive skills with relation to level of education. He was of the view that the social cultural level is based on the last education achieved by the person which develops not only professional skills but also cognitive skills for the improvement in their activities of daily life.

\subsection{Data Processing}

The data was collected and was placed in SPSS software version 25 for analysis.

Wilson et al. [11] have previously carried out principal component analysis and Boucard et al. [27] carried out Cronbach's alpha coefficient to assess the composite cognition score which was measured as a single latent factor.
The purpose of the test was to check the validity and the reliability of the executive functioning composite score.

In the $2^{\text {nd }}$ step, t-test was performed to compare the male and female according to socio-demographic variables, physical exercise practice (recent and long-term) and cognitive scores. The analysis provided us to measure the role of gender in physical exercise practice.

In the $3^{\text {rd }}$ step, Pearson correlations were carried out to find out the relationship between the different variables in this study.

In the $4^{\text {th }}$ step, a simple linear regression analysis was carried out to find out the relationship between the age and cognation.

In the $5^{\text {th }}$ step, linear regression analysis was carried out to check the strength of cognitive functions and age relationship with the addition of socio-cultural level control.

\subsection{Test of H1: Effect of Physical Exercise Activity on Cognitive Decline}

Model 1 was used to measure the moderating role of physical exercise activity on cognitive aging. The Model 1 test is broken down into several statistical analysis steps, which will be presented as follows:

a. Analysis of the simple effects of age and physical exercise activity on cognition.

b. Analysis of the interaction effect of age and physical exercise activity on cognition.

c. In case of significance of the interaction at the end of step b: test of the model's resistance to the addition of the socio-cultural level (SCL) as a control variable.

d. In case of significance of the interaction at the end of step c: separate analyses of the simple effect of age on cognition for different levels of physical exercise activity (high / medium / low / high / low). / bottom).

Finally, a summary table of all these steps has been proposed for each analysis in order to provide the details of the results.

Each of these steps have been carried out to measure the impact of recent physical exercise activity in the first instance (model 1A corresponding to H1A), then the impact of physical exercise activity over the long term in the second instance (model 1B corresponding to H1B).

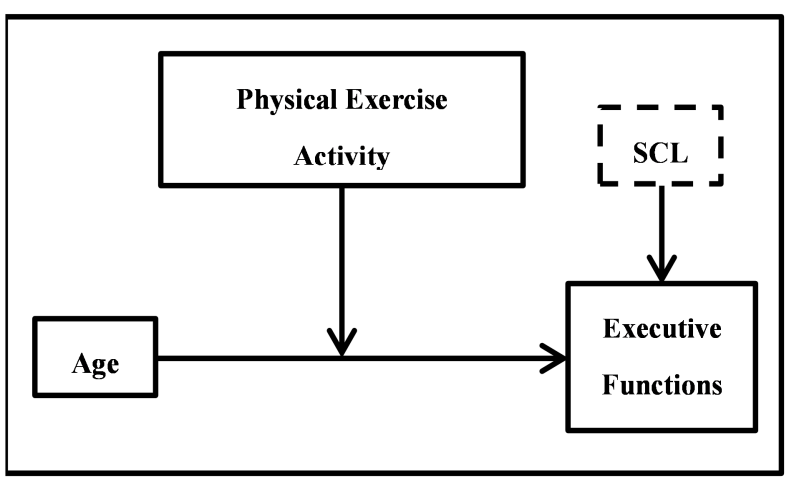

Figure 9. Model 1_Moder effect of physical exercise activity on the agecognition relationship, with socio-cultural level control (SCL). 
H2 test: Moderating role of gender on the impact of physical exercise activity on cognitive decline

A second model (model 2) was tested to measure the additive moderating role of gender on the impact of physical exercise activity on age-related cognitive decline (see Figure 10). Model 2 has several stages, which will be presented as follows:

a. Analysis of the simple effects of age, gender and physical exercise activity (PEA) on cognition.

b. Analysis of the effects of double age $\mathrm{x}$ gender, age $\mathrm{x}$ PEA, gender $x$ PEA interactions on cognition.

c. Analysis of the effect of triple age $x$ gender $x$ PEA interaction on cognition.

d. If the triple interaction is significant at the end of step c: test of the model's resistance to the addition of the socio-cultural level (SCL) as a control variable.

e. If the triple interaction is significant after step $d$ : separate analyzes of the interaction effect age x PEA on cognition for Females vs. Males.

Finally, a summary table of all these stages will be proposed for each analysis in order to provide details of the results.

As in model 1, each of these steps was carried out for recent physical exercise activity first (model 2A corresponding to $\mathrm{H} 2 \mathrm{~A}$ ), then for long-term physical exercise activity in the second phase (model 2B corresponding to $\mathrm{H} 2 \mathrm{~B}$ ).

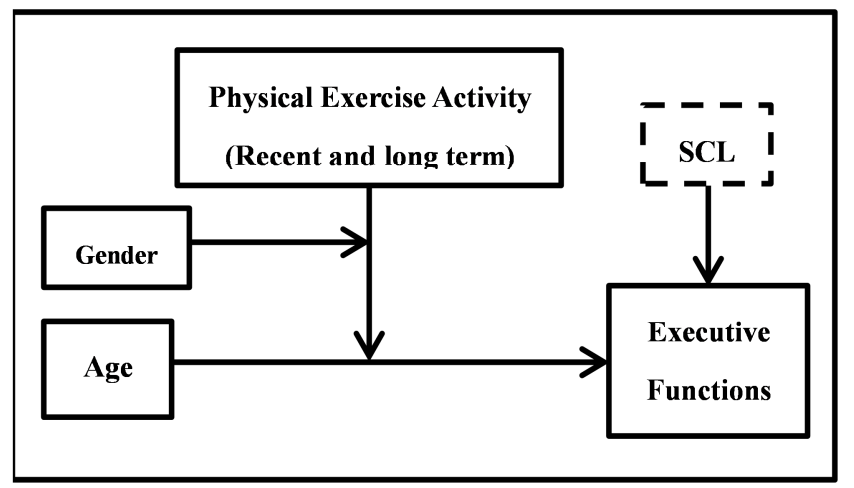

Figure 10. Model 2_Moder effect of gender and physical exercise activity on the age-cognition relationship, then model resistance test to the addition of the SCL as a control variable.

In models 1 and 2, the composite score of executive functions constitutes the criterion variable, age is treated as a continuous variable, and physical exercise activity is considered as a continuous moderating variable in the agecognition relationship. For model 2, gender is treated as a dichotomous moderating variable. Finally, the resistance of each of the models is tested by adding the SCL as a control variable, in order to avoid the theoretical bias linked to this variable playing a crucial role on cognition.

\section{Results}

\subsection{Validity of the Composite Score to Evaluate Cognitive Executive Functions}

Executive functions are the activities of daily living and IADL are considered too important to measure cognitive functions in the senior citizens for the purpose of composite score which have to be calculated and their internal reliability has to be verified through Cronbach's alpha. In this very particular study the value of Cronbach's alpha comes to be 0.88 . The result shows that the composite scores of executive functions measure is a single dimension latent construct.

Scree test is considered to be a single factor solution which provides range from 0.73 to 0.89 when having a total variance of $67.2 \%$. It means that the composite score are reliable to measure the cognitive functions in the senior citizens.

\subsection{Socio Demographics Measurements of Physical Exercise Activity and Cognitive Scores in Both the Genders}

The socio-demographic factors, physical exercise activity (recent and long term) and cognitive scores needs to be compared in both the genders. It is important that there is difference in the scores of male and female which shows that the female are having better physical exercise activity and have better cognitive functions. It has been observed that there is no significant different between both the genders on the basis of recent physical exercise activities but the difference has been noted in the long term activity of physical exercise activity which provide a significant improvement in the cognitive executive functions of the female. It has also been observed that the Females are more active physically and are hence having more hours of physical exercise activity than man $(\mathrm{t}(137)=2.86, \mathrm{p}<.01)$.

Table 2. Characteristics of the study sample 1.

\begin{tabular}{llll}
\hline Variables & $\begin{array}{l}\text { Females N=69 A } \\
\text { (SD) }\end{array}$ & $\begin{array}{l}\text { Males N=68 } \\
\text { A (SD) }\end{array}$ & t test \\
\hline Age & $48.26(17.99)$ & $49.31(17.82)$ & -0.33 \\
Years of study & $13.88(3.26)$ & $14.45(3.29)$ & -0.35 \\
Socio-cultural level & $3.97(1.23)$ & $3.98(1.22)$ & -0.89 \\
Executive functions & $0.03(1.00)$ & $-0.03(0.93)$ & 0.38 \\
Recent PEA Hours / week & $2.89(3.89)$ & $3.59(4.38)$ & -1.14 \\
Recent PEA MET / week & $17.54(24.08)$ & $27.63(47.96)$ & -1.78 \\
Long term PEA Hours / week & $2.37(2.75)$ & $4.11(4.16)$ & $-2.86^{\mathrm{b}}$ \\
Long-term PEA MET / week & $45.88(48.43)$ & $89.01(86.24)$ & $-3.58^{\mathrm{a}}$ \\
\hline
\end{tabular}

Note: $\mathrm{A}=$ Average. $\mathrm{SD}=$ Standard deviation. $\mathrm{PEA}=$ Physical Exercise Activity. MET=Metabolic Equivalent. ${ }^{\mathrm{a}} \mathrm{p}<.001 ;{ }^{\mathrm{b}} \mathrm{p}<.01 ;{ }^{\mathrm{c}} \mathrm{p}<.05$.

\subsection{Correlations Between Study Variables}

The correlation matrix makes it possible to observe the basic links between the different variables treated within this study (see Table 3).

Table 3. Matrix of correlations of the variables of study 1.

\begin{tabular}{llllllll}
\hline Variables & $\mathbf{1}$ & $\mathbf{2}$ & $\mathbf{3}$ & $\mathbf{4}$ & $\mathbf{5}$ & $\mathbf{6}$ & $\mathbf{7}$ \\
\hline Age & & & & & & & \\
Duration of study & 6 months & & & & & & \\
Socio-cultural level & $0.25^{\mathrm{b}}$ & $0.85^{\mathrm{a}}$ & & & & \\
Executive functions & $0.59^{\mathrm{a}}$ & $0.52^{\mathrm{a}}$ & $0.51^{\mathrm{a}}$ & & & \\
Recent PEA Hours / & 0.05 & $0.21^{\mathrm{c}}$ & $0.32^{\mathrm{a}}$ & 0.05 & & \\
week & & & & & & \\
Recent PEA MET / & $0.17^{\mathrm{c}}$ & $0.18^{\mathrm{c}}$ & $0.26^{\mathrm{b}}$ & 0.03 & $0.94^{\mathrm{a}}$ & \\
week & & 0.12 & 0.15 & $0.26^{\mathrm{b}}$ & $0.36^{\mathrm{a}}$ & $0.43^{\mathrm{a}}$ \\
Long term PEA Hours & $0.42^{\mathrm{a}}$ & 0.12 & \\
\hline
\end{tabular}




\begin{tabular}{llllllll}
\hline Variables & $\mathbf{1}$ & $\mathbf{2}$ & $\mathbf{3}$ & $\mathbf{4}$ & $\mathbf{5}$ & $\mathbf{6}$ & $\mathbf{7}$ \\
\hline $\begin{array}{l}\text { / week } \\
\begin{array}{l}\text { Long-term PEA MET } \\
\text { / week }\end{array}\end{array}$ & $0.21^{\mathrm{c}}$ & 0.06 & 0.11 & 0.16 & $0.33^{\mathrm{a}}$ & $0.38^{\mathrm{a}}$ & $0.80^{\mathrm{a}}$ \\
\hline
\end{tabular}

Note: PEA=Physical Exercise Activity. MET=Metabolic Equivalent. ${ }^{\mathrm{a}} \mathrm{p}<.001$; ${ }^{\mathrm{b}} \mathrm{p}<.01 ;{ }^{\mathrm{c}} \mathrm{p}<.05$.

\subsection{Relationship Between Age and Executive Functions}

Age has been considered a continuous predictor, consistent with the theory that an adult's cognition decreases with advancing age (Hertzog et al., 2009). The purpose of this analysis is therefore to measure the basic relationship between age and cognition in order to verify the validity of our basic statistical models. The results show that age is inversely related to cognitive functions $(\beta=-.596, \mathrm{p}<.001)$ resulting in a significant decline in cognition as age advances (see Figure 11). This model, composed solely of age as a predictor, explains $35.5 \%$ of the variance in executive functions $(\mathrm{F}(1.133)=73.185, \mathrm{p}<.001)$.

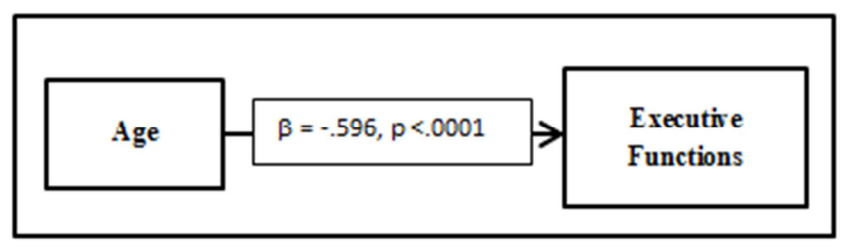

Figure 11. Base of the statistical model representing the relationship between age (continuous predictor) and executive functions (composite score).

In addition, the linear trend line significantly shows that the decline begins in early adulthood (see Figure 12).

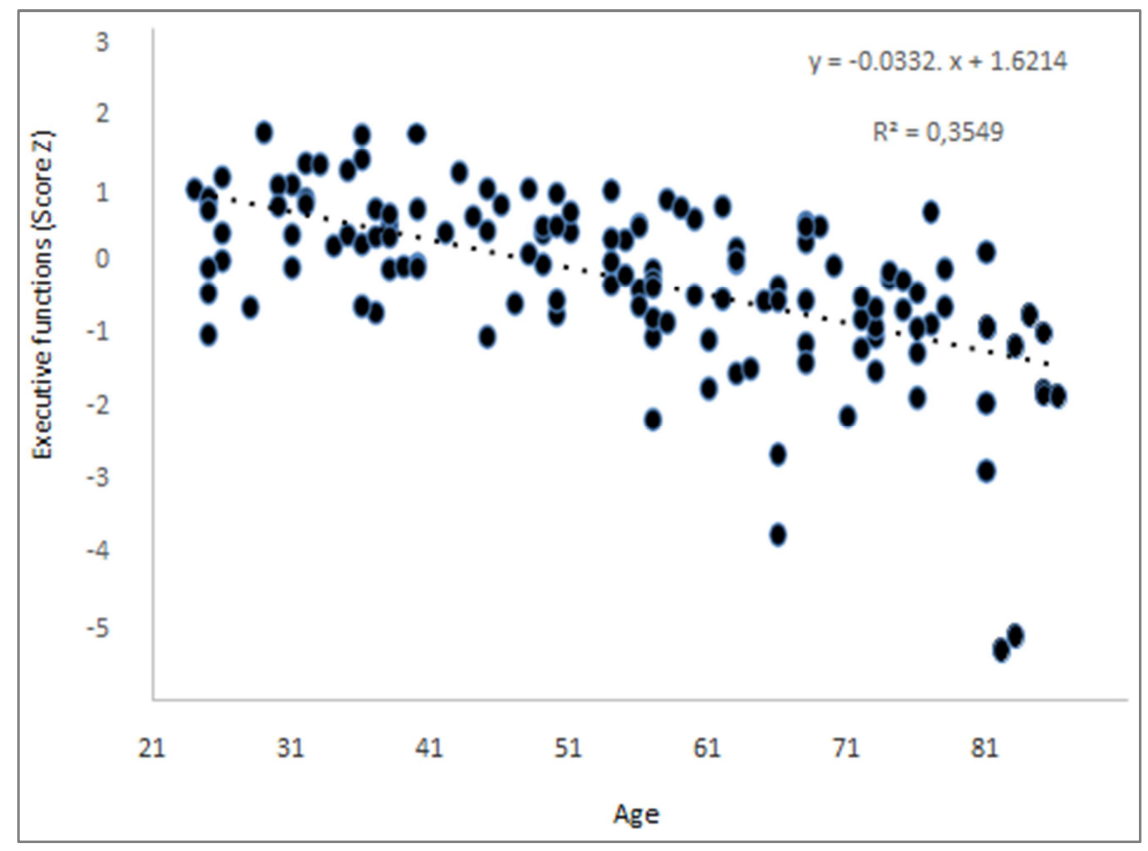

Figure 12. Basic relationship between age and cognition

\subsection{Impact of the Socio-cultural Level}

Regression analysis shows a significant positive link between SCL and cognitive performance $(\beta=.381, \mathrm{p}<.001)$. The variable SCL alone explains a little more than a quarter of the variance in cognitive functions $\left(\mathrm{R}^{2}=25.6 \%\right)$. Our research is based on the inverse relationship between age and cognition $(\beta=0.596, p<.001)$. Since the SCL variable plays an important role in cognitive performance, we want to verify the relationship of cognitive functions and SCL. The significance of the inverse relationship between age and cognition $(\beta=0.496, p<.001)$ is maintained despite the addition of the variable SCL to the model.

\subsection{Analysis of Models 1a and 1b: Moderating Effect of Physical Exercise Activity on Age-related Cognitive Decline}

The purpose of these analyzes is to verify our hypotheses regarding the effects of physical exercise activity on cognitive aging:

H1-a: Recent physical exercise activity helps limit agerelated cognitive decline.

H1-b: Long-term physical exercise activity protects against age-related cognitive decline.

\subsection{Analysis of the Impact of Recent Physical Exercise Activity on the Age-cognition Relationship}

Details of the results of each step of the analysis are presented in Table 4.

a. Analysis of simple effects: age and recent physical exercise activity on cognition.

The introduction of the variable "recent physical exercise activity" into the basic age-cognition model does not lead to any significant increase in the explained variance of cognition $\left(\Delta \mathrm{R}^{2}=.004, \mathrm{p}=.354\right)$. 
b. Analysis of the effect of interaction between age and recent physical exercise activity on cognition.

The addition of the interaction term age $\mathrm{x}$ "recent physical exercise activity" also does not lead to any significant increase in the explained variance of cognition $\left(\Delta R^{2}=.004\right.$, $\mathrm{p}=.082)$.

Table 4. Model 1 of normalized $\beta$ values from multiple regression analyzes for "recent physical exercise activity".

\begin{tabular}{lllll}
\hline \multirow{2}{*}{ Variables } & \multicolumn{4}{l}{ Recent Physical Exercise Activities } \\
\cline { 2 - 5 } & Step 1 & Step 2 & Step 3 & Step 4 \\
\hline Age & $0.598^{\mathrm{a}}$ & $0.607^{\mathrm{a}}$ & $0.639^{\mathrm{a}}$ & $0.505^{\mathrm{a}}$ \\
Recent PEA & & 0.066 & 0.114 & 0.030 \\
Recent PEA x Age & & & 0.132 & 0.082 \\
SCL & & & & $0.395^{\mathrm{a}}$ \\
$\mathrm{R}^{2}$ & $0.355^{\mathrm{a}}$ & $0.359^{\mathrm{a}}$ & $0.374^{\mathrm{a}}$ & $0.502^{\mathrm{a}}$ \\
$\Delta \mathrm{R}^{2}$ & 0.355 & 0.004 & 0.015 & $0.128^{\mathrm{a}}$ \\
\hline
\end{tabular}

Note: PEA=Physical Exercise Activity. $\mathrm{SCL}=$ Socio-Cultural Level. ${ }^{\mathrm{a}} \mathrm{p}<.001$; ${ }^{b} \mathrm{p}<.01 ;{ }^{\mathrm{c}}<<.05$.

\subsection{Analysis of the Impact of Long-term Physical Exercise Activity (PEA) on the Relationship Between age and Cognition}

The details of the results of each step of the analysis are presented in Table 5.

a. Analysis of simple effects: age and long term PEA on cognition.

The introduction of the variable "long-term physical exercise activity" into the basic age-cognition model lead to an insignificant increase in the explained variance of cognition $\left(\Delta \mathrm{R}^{2}=.002, \mathrm{p}=.562\right)$.

b. Analysis of the interaction effect between age and long term PEA on cognition.

The addition of the interaction term age $\mathrm{x}$ "long-term physical exercise activity" also lead to a significant increase in the explained variance of cognition $\left(\Delta \mathrm{R}^{2}=.004, \mathrm{p}=.361\right)$.

Table 5. Model 1 of normalized $\beta$ values from multiple regression analyzes for "long-term physical exercise activity".

\begin{tabular}{lllll}
\hline \multirow{2}{*}{ Variables } & \multicolumn{4}{l}{ Long Term Physical Exercise Activities } \\
\cline { 2 - 5 } & Step 1 & Step 2 & Step 3 & Step 4 \\
\hline Age & $0.596^{\mathrm{a}}$ & $0.587^{\mathrm{a}}$ & $0.590^{\mathrm{a}}$ & $0.496^{\mathrm{a}}$ \\
Long Term PEA & & 0.042 & 0.041 & 0.019 \\
Long Term PEA x Age & & & 0.064 & 0.011 \\
SCL & & & & $0.381^{\mathrm{a}}$ \\
$\mathrm{R}^{2}$ & $0.355^{\mathrm{a}}$ & $0.357^{\mathrm{a}}$ & $0.361^{\mathrm{a}}$ & $0.493^{\mathrm{a}}$ \\
$\Delta \mathrm{R}^{2}$ & 0.355 & 0.002 & 0.004 & $0.133^{\mathrm{a}}$ \\
\hline
\end{tabular}

Note: PEA=Physical Exercise Activity. $\mathrm{SCL}=$ Socio-Cultural Level. ${ }^{\mathrm{a}} \mathrm{p}<.001$; ${ }^{\mathrm{b}} \mathrm{p}<.01 ;{ }^{\mathrm{c}} \mathrm{p}<.05$.

\subsubsection{Analysis of Models $2 a$ and 2b: Moderating Role of gender in the Relationship Between Recent Physical Exercise Activity and Age-related Cognitive Function}

The purpose of these analyzes is to verify our hypotheses concerning the additional moderating role of gender in the relationship between physical exercise activity and agerelated cognitive decline:

H2-a: Recent physical exercise activity has more impact on the cognitive aging of males and female.
H2-b: Long-term physical exercise activity has a more impact on the cognitive aging of male and females.

\subsubsection{Analysis of the Role of Gender in the Relationship Between Recent Physical Exercise Activity and Age-related Cognitive Function}

The details of the results at each stage of the analysis are presented in Table 6.

a. Analysis of simple effects: age, gender, recent physical exercise activity (PRA) on cognition

The introduction of the variables "recent physical exercise activity" and "gender" into the basic age-cognition model does not lead to an insignificant increase in the explained variance of cognition $\left(\Delta \mathrm{R}^{2}=.004, \mathrm{p}=.649\right)$.

b. Analysis of the effects of dual interactions: age $\mathrm{x}$ gender, age $x$ PEA, gender $x$ PEA on cognition

Adding the three double interactions to the model leads to an insignificant increase in the explained variance of cognition $\left(\Delta \mathrm{R}^{2}=.023, \mathrm{p}=.136\right)$ with a non-significant contribution from the three double interactions in the recent physical exercise activity.

c. Analysis of the triple interaction effect: age $\mathrm{x}$ gender $\mathrm{x}$ PEA on cognition

The entry of the triple age $\mathrm{x}$ gender $\mathrm{x}$ PEA interaction in the model leads to a non-significant increase in the explained variance $\left(\Delta \mathrm{R}^{2}=.012, \mathrm{p}=.123\right)$ in recent physical exercise activity.

Table 6. Model 2 of normalized $\beta$ values from multiple regression analyzes for "recent physical exercise activity".

\begin{tabular}{llllll}
\hline \multirow{2}{*}{ Variables } & \multicolumn{5}{c}{ Recent Physical Exercise Activities } \\
\cline { 2 - 6 } & Step 1 & Step 2 & Step 3 & Step 4 & Step 5 \\
\hline Age & $0.596^{\mathrm{a}}$ & $-.607^{\mathrm{a}}$ & $0.740^{\mathrm{a}}$ & $0.742^{\mathrm{a}}$ & $0.565^{\mathrm{a}}$ \\
Gender & & 0.006 & .006 & 0.028 & 0.088 \\
Recent PEA & & 0.065 & 0.253 & 0.173 & .112 \\
Age x Gender & & & .127 & .143 & .103 \\
Recent PEA x Age & & .107 & $.359^{\mathrm{c}}$ & .283 \\
Recent PEA x Gender & & & .154 & .108 & 0.044 \\
Recent PEA x Age x Gender & & & & 0.286 & 0.235 \\
SCL & & & & & $.399^{\mathrm{a}}$ \\
$\mathrm{R}^{2}$ & $.350^{\mathrm{a}}$ & $.345^{\mathrm{a}}$ & $.353^{\mathrm{a}}$ & $.360^{\mathrm{a}}$ & $.486^{\mathrm{a}}$ \\
$\Delta \mathrm{R}^{2}$ & .355 & .004 & .023 & .012 & $.124^{\mathrm{a}}$ \\
\hline
\end{tabular}

Note: PEA=Physical Exercise Activity. $\mathrm{SCL}=$ Socio0Cultural Level. ${ }^{\mathrm{a}} \mathrm{p}<.001$; ${ }^{\mathrm{b}} \mathrm{p}<.01 ;{ }^{\mathrm{c}} \mathrm{p}<.05$.

\subsubsection{Analysis of the Role of Gender in the Relationship Between Long-term Physical Exercise Activity (PEA) and Age-related Cognitive Function}

The details of the results at each stage of the analysis are presented in Table 7.

a. Analysis of simple effects: age, gender, PEA on cognition

The introduction of the variables "long-term physical exercise activity" and "gender" into the basic age-cognition model lead to an insignificant increase in the explained variance of cognition $\left(\Delta \mathrm{R}^{2}=.003, \mathrm{p}=.771\right)$.

b. Analysis of the effects of dual interactions: age $\mathrm{x}$ gender, age $x$ PEA, gender $x$ PEA on cognition

Adding the three double interactions to the model lead to an insignificant increase in the explained variance of 
cognition $\left(\Delta \mathrm{R}^{2}=.008, \mathrm{p}=.671\right)$.

c. Analysis of the triple interaction effect: age $\mathrm{x}$ gender $\mathrm{x}$ PEA on cognition

The introduction of the triple age $x$ gender $x$ PEA interaction in the model leads to a significant increase in the explained variance $\left(\Delta \mathrm{R}^{2}=.039, \mathrm{p}=.005\right)$ with a significant contribution of the triple interaction $(\beta=0.496, p=.005)$.

d. Test of the model's resistance to the addition of the socio-cultural level (SCL) as a control variable

Adding the SCL to the model leads to a significant increase in the explained variance $\left(\Delta \mathrm{R}^{2}=.118, \mathrm{p}<.001\right)$ with a significant contribution from the $\operatorname{SCL}(\beta=.365, \mathrm{p}<.001)$. Despite the introduction of the SCL into the model, the contribution of the triple age $\mathrm{x}$ gender $\mathrm{x}$ PEA interaction remains significant $(\beta=0.749, \mathrm{p}=.021)$.

e. Detailed analyzes of the effect of age $x$ physical exercise activity interaction on cognition for Females vs. for Males

Regression analyzes performed separately in Females and in Males show that there is a moderating effect of long-term physical exercise activity on cognitive aging in Females $(\beta=.222, p=.040)$ but not in Males $(\beta=0.097, p=.311)$.

Note: The regression slopes are derived from hypothetical individuals who are a standard deviation above or below the average age and the average of PEA by gender group (Males vs. Females). The "executive functions" are the average of the $\mathrm{z}$ scores of the Matrix reasoning test, the $3 \mathrm{rd}$ and the 4th condition of the Stroop test, DSST and TMT B-A.

Table 7. Model 2 of normalized $\beta$ values from multiple regression analyzes for "long-term physical exercise activity".

\begin{tabular}{llllll}
\hline \multirow{2}{*}{ Variables } & \multicolumn{5}{c}{ Long Term Physical Exercise Activities } \\
\cline { 2 - 6 } & Step 1 & Step 2 & Step 3 & Step 4 & Step 5 \\
\hline Age & $0.596^{\mathrm{a}}$ & $0.584^{\mathrm{a}}$ & $0.637^{\mathrm{a}}$ & $0.480^{\mathrm{a}}$ & $0.447^{\mathrm{a}}$ \\
Gender & & 0.052 & .085 & 0.329 & .236 \\
Long Term PEA & & 0.032 & 0.037 & 0.155 & 0.147 \\
Age x Gender & & & .055 & $.517^{\mathrm{b}}$ & $.339^{\mathrm{c}}$ \\
Long Term PEA x Age & & & .074 & 0.017 & .031 \\
Long Term PEA x Gender & & & 0.039 & 0.234 & 0.168 \\
Long Term PEAxAgexGender & & & & $0.496^{\mathrm{b}}$ & $0.364^{\mathrm{c}}$ \\
SCL & & & & & $.365^{\mathrm{a}}$ \\
$\mathrm{R}^{2}$ & $.355^{\mathrm{a}}$ & $.358^{\mathrm{a}}$ & $.365^{\mathrm{a}}$ & $.404^{\mathrm{a}}$ & $.522^{\mathrm{a}}$ \\
$\Delta \mathrm{R}^{2}$ & .355 & .003 & .008 & $.039^{\mathrm{b}}$ & $.118^{\mathrm{a}}$ \\
\hline
\end{tabular}

Note: PEA=Physical Exercise Activity. $\mathrm{SCL}=$ Socio0Cultural Level. ${ }^{\mathrm{a}} \mathrm{p}<.001$; ${ }^{\mathrm{b}} \mathrm{p}<.01 ;{ }^{\mathrm{c}} \mathrm{p}<.05$.

Result of our study showed that the Females who were actively engaged in socio-cultural activities and physical exercise activities were having better executive cognitive functions.

From our study it has been found out that the long term physical exercise activity in the Females has decline the cognitive impairment which is in line with our hypothesis H2-b which states that the long-term physical exercise activity will be more beneficial to the Females as compare to the Males in old age.

The difference in results between male and female in our study may be due to psychological, biological differences and gender influence in the society.

\section{Discussion}

This study has been carried out in order to find out the impact of recent or long term physical exercise activity on age related cognitive functions in male and female.

The results of this studies shows that the recent physical exercise are less effective in preserving cognitive functions in the senior citizens regardless of male or female gender. This result shows that hypothesis 2 seems to be approved as a result of this observation. The first hypothesis stated that recent physical exercise activity can limit the age related cognitive decline. Our results showed that the recent physical exercise activity in short term does not provide exclusive evidence with effect of recent short term activities.

Anguera et al. carried out an early study based on that the cognitive functions decrease with the increasing age. He was also of the view that the cognitive decline starts in the adult hood but increases with the increase in age. [28]

Bherer et al. carried out a study on the young older adults with increased recent physical exercise activities. He found out that the physical exercise activity improve the cognitive functions in the younger old adults between the ages of 61-70 years which is contrary to the results of our present study. [29]

Nagamatsu et al. carried out another study on the healthy older persons who does not have a dementia. He found out that the long term physical exercise activity improved the cognitive functions in the healthy older adults. [30]

Jager et al. carried out meta-analysis on the different studies in relation to cognitive functions and physical exercise. He found out that there was limitation to study intervention while converting composite scores into praxis which leads to difference in results on the basis of different modifiers. [31]

Sodergren carried out a research based on various ages groups. He found out that it is very difficult for the individuals to carry out long duration Aerobic physical exercise for longer duration of period specially when they are in the increasing age. So it is very difficult to conduct a long durational study on the senior citizens in relation to physical exercise and cognition. [32]

Kelly et al. carried out a study for one year with the measurement of cognitive level after the intervention of physical exercise activity at different times. He observed that the short time physical exercise does not produce any significant improvement in the cognitive level of senior citizens. [33]

Gearin \& Fien carried out another study for 12 months to find out the relationship of physical exercise and its impact on its cognitive function on its senior citizens. He was of the view that the short term exercise may improve cognitive level in the health old adults. But will disappear in the short pace. He found out that the regular exercise of more than one year can produce significant effect on the cognitive levels of the healthier old adults. [34]

Middleton et al. carried out a research on 9445 Females having age of 65 years and above. The participants which were included physical healthy and having low risk of developing age related cognitive decline. The subject indexes were divided into different age groups. It was found out that 
the physical exercise activity can be used to preventive to cognitive decline in old Females having risk of developing cognitive decline. [35]

Kareholt et al. carried out another study between the various age groups between $46-76$ years to found out that the Females were having more physical exercise activities as compare to the Males and hence are having low cognitive decline. [5]

Castonguay et al. carried out a research on the basis of endocrine system and hormone functioning in the male and female. He was of the view that the biological difference plays an important role in carrying out long term physical exercise activity in the Females that prevent them from cognitive decline in old age. These findings are consistent with our study. [36]

Ruigrok et al. carried out another research on the brain structure difference in male and female, he found out that the difference in brain size and organization play an important role to save the cognitive decline in the Females as compare to man. [37]

Boulton et al. wanted to check multiple influences on participating in physical activity in older age. He developed a socio-ecological approach to verify the influence of physical exercise activity on the cognitive functions on ADL and IADL. He found out that the physical exercise activity plays an important role in maintaining cognitive ADL and IADL in the senior citizens. [38]

Moreno-Agostino et al. collected the evidence from eight cohort studies in order to find out the impact of physical activity on healthy ageing trajectories. He found out that the physical exercise activity played an important role in maintaining the cognitive functions in senior citizens. [39]

Abraham carried out another study to find out the relationship of cognitive functions in man and Females. He found out that the hormones and organization of brain were playing an important role in saving the cognitive decline in the Females. [40]

The result of current physical exercise activity on the cognitive executive functioning in male and female does not show any difference in the short term. This was due to a reason that a stimulation of hormones and other biological functions takes time to initiate. Once develop, have long lasting impact in the prevention of cognitive decline in the Females as compare to Males.

Venezia et al. carried out a research on physiological responses in the man and Females to the exercise. They found out that the physical exercise improve the conditions in the females much better as compare to male. [41]

Baker et al. carried out a six month high density Aerobic activity to check the cardio respiratory fitness and body fat reduction in male and female. He found out that the cognitive effect was recorded in male and female. The physical exercise activity had improved cognitive task, reduce fasting plasma level of insulin and promoted glucose regulation, cortisol and brain drive, neuro tropic factors in the female. In male, improved cognitive performance due to increase plasma insulin level were also recorded. Female cognitive response improvement was much greater as compare to male. Further research of the moderating effect of gender related biological factors will provide a new dimension on physical exercise activity related cognitive functions. [42]

The gender effect on the cognitive functions is needed to be explained. Gender is defined as "biological distinguish between males and a females in relation to reproductive functions"

Habacha was of the view that cognitive functions are related to the different performances related to the different genders. He was of the view that regardless of the physical fitness and choice of physical exercise activity may be based on cognitive stimuli which may act on brain plasticity. [43]

Bann et al. carried out a study to find out the impact of socioeconomic differences in the structured physical activity. He compared health education on the prevention of major mobility disability in the older adults. He found out that the structured physical exercise activity not only improved the mobility but also improved the cognitive functions in the senior citizens. [44]

Young carried out a research the importance of physical exercise density and fitness improvement in the male and female of 60 years and above. He found out that the cognitive benefits obtained by the Females as compare to the male were greater in females due to their endurance to the sociocultural norms. [45]

The psychological factors also play an important role to explain the relationship between the physical exercise and cognitive function.

Bale \& Epperson was of the view that the stress reflects the male and female gender differently. Hence, physical exercise activity may produce different results due to different psychological response due to socio-cultural factors. [46]

Our study has been carried out in a period of six months. The duration of the physical exercise was try to maintain at one hour per week. The participation of the male were greater in number as compare to females who were actively engaged in physical exercise activities at home. The lack of participation by the Females lead to the question of physical exercise activity before the researcher.

To assess the impact of long term activity on age related cognitive decline were also carried out for over a period of more than six months. Our study showed that the long term physical exercise has great impact on that cognitive functions. Especially in the Females who are actively involved in the socio cultural activities.

This is the first study which has been carried out on the relationship between the recent or long term physical exercise activity and cognitive functions in male and female.

\section{Limitation and Further Recommendations}

The main objective of the study was to observe moderating effect of recent or long term physical exercise activity on the cognitive executive functions in the adulthood based on gender. A small sample was taken and hence the generalizability of the study is the limited. Hence it is 
recommended that the more comprehensive study for longer duration of period should be carried out to see the generalize effect of the variables.

\section{Conclusion}

It has been concluded from the study that the recent physical exercise activities cannot produce significant results in prevention of cognitive decline in the senior citizens both in males and females. However, the long term physical exercise activity in the females can prevent more cognitive decline as compare to male. This study has also opened up new avenues of research to understand what type of physical activity is most conducive related to cognation. We are able to find out relationship that enrich behaviours and cognitive functions in males and females in the senior citizens.

\section{References}

[1] Saracli, O., Akca, A. S. D., Atasoy, N., Onder, O., Şenormanc1, O., Kaygisiz, İ., \& Atik, L. (2015). The Relationship between Quality of Life and Cognitive Functions, Anxiety and Depression among Hospitalized Elderly Patients. Clinical Psychopharmacology and Neuroscience, 13 (2), 194-200. doi: 10.9758/cpn.2015.13.2.194.

[2] Andel, R., Silverstein, M., \& Kareholt, I. (2014). The role of midlife occupational complexity and leisure activity in latelife cognition. The Journals of Gerontology Series B: Psychological Sciences and Social Sciences, 70 (2), 314-321. doi: $10.1093 /$ geronb/gbu110.

[3] Gow, A. J., Pattie, A., \& Deary, I. J. (2017). Lifecourse Activity Participation From Early, Mid, and Later Adulthood as Determinants of Cognitive Aging: The Lothian Birth Cohort 1921. The Journals of Gerontology Series B: Psychological Sciences and Social Sciences, 72 (1), 25-37. doi: $10.1093 /$ geronb/gbw124.

[4] Prakash, R. S., Voss, M. W., Erickson, K. I., \& Kramer, A. F. (2015). Physical exercise activity and cognitive vitality. Annual review of psychology, 66, 769-797. doi: 10.1146/annurev-psych-010814- 015249.

[5] Kareholt, I., Lennartsson, C., Gatz, M., \& Parker, M. G. (2011). Baseline leisure time activity and cognition more than two decades later. International journal of geriatric psychiatry, 26 (1), 65-74. doi: 10.1002/gps.2490.

[6] Abou-Dest, A., Albinet, C. T., Boucard, G., \& Audiffren, M. (2012). Swimming as a Positive Moderator of Cognitive Aging: A Cross-Sectional Study with a Multitask Approach. Journal of Aging Research, 2012. doi: 10.1155/2012/273185.

[7] Etnier, J. L., \& Chang, Y.-K. (2009). The effect of physical exercise activity on executive function: a brief commentary on definitions, measurement issues, and the current state of the literature. Journal of Sport and Exercise Psychology, 31 (4), 469-483. doi: 10.1123/jsep.31.4.469.

[8] Barnes, D. E., Santos-Modesitt, W., Poelke, G., Kramer, A. F., Castro, C., Middleton, L. E., \& Yaffe, K. (2013). The mental Activity and eXercise (MAX) trial: a randomized controlled trial to enhance cognitive function in older adults. JAMA internal medicine, 173 (9), 797-804. doi: 10.1001/jamainternmed.2013.189.
[9] Barnes, L. L., De Leon, C. M., Wilson, R. S., Bienias, J. L., \& Evans, D. A. (2004). Social resources and cognitive decline in a population of older African Americans and whites. $\begin{array}{llll}\text { Neurology, } & 63 & (12), & 2322-2326 .\end{array}$ 10.1212/01.WNL.0000147473.04043.B3.

[10] Oswald, W. D., Gunzelmann, T., Rupprecht, R., \& Hagen, B. (2006). Differential effects of single versus combined cognitive and physical training with older adults: the $\operatorname{SimA}$ study in a 5- year perspective. European Journal of Ageing, 3 (4), 179-192. doi: 10.1007/s10433-006- 0035-z.

[11] Wilson, R. S., Krueger, K. R., Arnold, S. E., Schneider, J. A., Kelly, J. F., Barnes, L. L.,... \& Bennett, D. A. (2007). Loneliness and risk of Alzheimer disease. Archives of general psychiatry, 64 (2), 234-240. doi: 10.1001/archpsyc.64.2.234.

[12] Arbuthnott, K., \& Frank, J. (2000). Trail making test, part B as a measure of executive control: validation using a setswitching paradigm. Journal of clinical and experimental neuropsychology, 22 (4), 518-528. doi: 10.1076/13803395(200008) 22: 4; 1-0; FT518.

[13] Kortte, K. B., Horner, M. D., \& Windham, W. K. (2002). The trail making test, part $\mathrm{B}$ : cognitive flexibility or ability to maintain set? Applied neuropsychology, 9 (2), 106-109. doi: 10.1207/S15324826AN0902_5.

[14] Pachana, N. A., Thompson, L. W., Marcopulos, B. A., \& Yoash-Gantz, R. (2004). California Older Adult Stroop test (COAST) development of a stroop test adapted for geriatric populations. Clinical gerontologist, 27 (3), 3-22. doi: 10.1300/j018v27n03_02.

[15] Salthouse, T. A., Atkinson, T. M., \& Berish, D. E. (2003). Executive functioning as a potential mediator of age-related cognitive decline in normal adults. Journal of Experimental Psychology: General, 132 (4), 566-594. doi: 10.1037/00963445.132.4.566.

[16] Makizako H, Shimada H, Doi T, et al. Predictive Cutoff Values of the Five-Times Sit-to-Stand Test and the Timed "Up \& Go" Test for Disability Incidence in Older People Dwelling in the Community. Physical therapy 2017; 97: 417-24. doi: 10.2522/ptj.20150665.

[17] Oreska L, Slobodova L, Vajda M, Kaplanova A, Tirpakova V, Cvecka J, et al. The effectiveness of two different multimodal training modes on physical performance in elderly. European journal of translational myology. 2020; 30 (1): 8820 . doi.org/10.4081/ejtm.2019.8820.

[18] Beck, A. T., Steer, R. A., \& Carbin, M. G. (1988). Psychometric properties of the Beck Depression Inventory: Twenty-five years of evaluation. Clinical psychology review, 8 (1), 77-100. doi: 10.1016/0272-7358(88) 90050-5.

[19] Arevalo-Rodriguez I, Smailagic N, Roqué I, Figuls M, Ciapponi A, Sanchez-Perez E, et al. Mini-Mental State Examination (MMSE) for the detection of Alzheimer's disease and other dementias in people with mild cognitive impairment (MCI). The Cochrane database of systematic reviews. 2015; (3): CD010783. https://doi.org/10.1002/14651858.CD010783.pub2.

[20] Ainsworth BE, Haskell WL, Herrmann SD, Meckes N, Bassett Jr. DR, Tudor-Locke C, et al. Compendium of Physical exercise activities 2011: A second update of MET codes and values. Medicine and sport and exercise science. 2011; $43 \quad$ (8): $\quad 1575-1581$. $10.1249 / \mathrm{mss} .0 \mathrm{~b} 013 \mathrm{e} 31821 \mathrm{ece} 12$. 
[21] Stroop, J. R. (1935). Studies of interference in serial verbal reactions. Journal of experimental psychology, 18 (6), 643.

[22] Scarpina F, Tagini S. The Stroop Color and Word Test. Frontiers in psychology. 2017; 8: 557. doi.org/10.3389/fpsyg.2017.00557.

[23] Diamond A. Executive functions. Annual review of psychology. 2013; 64: 135-168. doi: 10.1146/annurev-psych113011-143750.

[24] Rouillard, M., Audiffren, M., Albinet, C., Ali Bahri, M., Garraux, G., \& Collette, F. (2016). Contribution of four lifelong factors of cognitive reserve on late cognition in normal aging and Parkinson's disease. Journal of Clinical and Experimental Neuropsychology, 39 (2), 142-162. doi: 10.1080/13803395.2016.1207755.

[25] Chung-Yi, L., \& Wu, S. C. (2002). Lifetime principal occupation and risk of cognitive impairment among the elderly. Industrial health, 40 (1), 7-13.

[26] Fujishiro K, MacDonald LA, Crowe M, McClure LA, Howard VJ, Wadley VG. The Role of Occupation in Explaining Cognitive Functioning in Later Life: Education and Occupational Complexity in a U.S. National Sample of Black and White Men and Women. The journals of gerontology, Series B, Psychological sciences and social sciences. 2019; 74 (7): 1189-1199. doi: 10.1093/geronb/gbx112.

[27] Boucard, G. K., Albinet, C. T., Bugaiska, A., Bouquet, C. A., Clarys, D., \& Audiffren, M. (2012). Impact of physical exercise activity on executive functions in aging: a selective effect on inhibition among old adults. Journal of Sport and Exercise Psychology, 34 (6), 808-827. doi: 10.1123/jsep. 34.6.808.

[28] Anguera, J. A., Boccanfuso, J., Rintoul, J. L., Al-Hashimi, O., Faraji, F., Janowich, J.,... \& Gazzaley, A. (2013). Video game training improves cognitive control in the elderly. Nature, 501 (7465), 97-101. doi: 10.1038 / nature12486.

[29] Bherer, L., Erickson, K. I., \& Liu-Ambrose, T. (2013). A Review of the Effects of Physical exercise activity and Exercise on Cognitive and Brain Functions in Older Adults. Journal of Aging Research, 2013, 1-8. doi: $10.1155 / 2013 / 657508$.

[30] Nagamatsu, L. S., Flicker, L., Kramer, A. F., Voss, M. W., Erickson, K. I., Hsu, C. L., \& Liu-Ambrose, T. (2014). Exercise is medicine, for the body and the brain. British Journal of Sports Medicine, 48 (12), 943-944. doi: 10.1136/bjsports-2013-093224.

[31] Jager, K., Schmidt, M., Conzelmann, A., \& Roebers, C. M. (2015). The effects of qualitatively different acute physical exercise activity interventions in real-world settings on executive functions in preadolescent children. mental Health and Physical exercise activity, 9, 1-9. doi: 10.1016/j.mhpa.2015.05.002.

[32] Sodergren, M. (2013). Quality of life predictors of healthy ageing in Males. Maturitas, 75 (2), 113-117. doi: 10.1016/j.maturitas.2013.02.011.

[33] Kelly, M. E., Loughrey, D., Lawlor, B. A., Robertson, I. H., Walsh, C., \& Brennan, S. (2014). The impact of exercise on the cognitive functioning of healthy older adults: A systematic review and meta-analysis. Ageing Research Reviews, 16, 1231. doi: 10.1016/j.arr.2014.05.002.

[34] Gearin, B. M., \& Fien, H. (2016). Translating the neuroscience of physical exercise activity to education. Trends in Neuroscience and Education, 5 (1), 12-19. doi: 10.1016/j.tine.2016.02.001.

[35] Middleton, L., Kirkland, S., Mitnitski, A., MacPherson, K., \& Rockwood, K. (2010). Physical exercise activity and cognition: Effect at mid-life versus late life. Alzheimer's \& Dementia, 7 (4), 614. doi: 10.1016/j.jalz.2011.05.1749.

[36] Castonguay, N., Lussier, M., Bugaiska, A., Lord, C., \& Bherer, L. (2015). Executive functions in Males and postmenopausal Females. Journal of clinical and experimental $\begin{array}{llll}\text { neuropsychology, } & 37 & \text { (2), } & 193-208 .\end{array}$ 10.1080/13803395.2014.1000267.

[37] Ruigrok, A. N., Salimi-Khorshidi, G., Lai, M.-C., BaronCohen, S., Lombardo, M. V., Tait, R. J., \& Suckling, J. (2014). A meta-analysis of gender differences in human brain structure. Neuroscience \& Bio behavioral Reviews, 39, 34-50. doi: 10.1016/j.neubiorev.2013.12.004.

[38] Boulton ER, Horne M, Todd C. Multiple influences on participating in physical activity in older age: Developing a social ecological approach. Health Expectations. 2018; 21 (1): 239-248. doi: 10.1111/hex.12608.

[39] Moreno-Agostino D, Daskalopoulou C, Wu YT, Koukounari A, Haro JM, Tyrovolas S, et al. The impact of physical activity on healthy ageing trajectories: evidence from eight cohort studies. The international journal of behavioral nutrition and

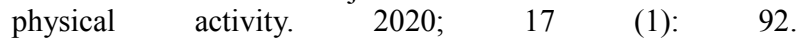
https://doi.org/10.1186/s12966-020-00995-8.

[40] Abraham, A. (2016). Gender and creativity: an overview of psychological and neuroscientific literature. Brain imaging and behavior, 10 (2), 609-618. doi: 10.1007/s11682-015-9410-8.

[41] Venezia, A. C., Guth, L. M., Sapp, R. M., Spangenburg, E. E., \& Roth, S. M. (2016). Gender-dependent and independent effects of long-term voluntary wheel running on Bdnf mRNA and protein expression. Physiology \& Behavior, 156, 8-15. doi: 10.1016/j.physbeh.2015.12.026.

[42] Baker, L. D., Frank, L. L., Foster-Schubert, K., Green, P. S., Wilkinson, C. W., McTiernan, A.,... \& Duncan, G. E. (2010). Effects of aerobic exercise on mild cognitive impairment: a controlled trial. Archives of neurology, 67 (1), 71-79. doi: 10.1001/archneurol.2009.307.

[43] Habacha, H., Molinaro, C., \& Dosseville, F. (2014). Effects of Gender, Imagery Ability, and Sports Practice on the Performance of a mental Rotation Task. The American journal of psychology, 127 (3), 313-323. doi: 10.5406/amerjpsyc.127.3.0313.

[44] Bann D, Chen H, Bonell C, Glynn NW, Fielding RA, Manini $\mathrm{T}$, et al. Socioeconomic differences in the benefits of structured physical activity compared with health education on the prevention of major mobility disability in older adults: the LIFE study. Journal of Epidemiology Community Health. 2016; 70 (9): 930-3. doi: 10.1136/jech-2016-207321.

[45] Young, J., Angevaren, M., Rusted, J., \& Tabet, N. (2015). Aerobic exercise to improve cognitive function in older people without known cognitive impairment. The Cochrane Library, 1- 141. doi: 10.1002/14651858.CD005381.pub4.

[46] Bale, T. L., \& Epperson, C. N. (2015). Gender differences and stress across the lifespan. Nature Neuroscience, 18 (10), 14131420. doi: $10.1038 / \mathrm{nn} .411$. 